\title{
Abrindo a caixa de ferramentas foucaultiana: delineando a governamentalidade global enquanto instrumento analítico das Relações Internacionais
}

\author{
Opening Foucault's toolbox: delineating global \\ governmentality as an analytical instrument for \\ International Relations
}

1. Mestra em Ciência Política pela Universidade Federal do Paraná (UFPR), é Professora de Relações Internacionais no Centro Universitário Curitiba (UNICURITIBA, Brasil), e atualmente é Doutoranda em Ciência Política no Programa de Pós-Graduação em Ciência

Política da Universidade Federal do Paraná (PPGCP-UFPR). É integrante do Núcleo de Estudos para a Paz (NEP) da Unila e do Núcleo de Pesquisa em Relações Internacionais (NEPRI) da UFPR Contato: natali.hoff@gmail.com. ORCID: https://orcid.org/0000-0003-2017-4940.

2. Doutor em Relações Internacionais pela Universidade de Coimbra,

é Professor Adjunto no curso de Relações Internacionais e Integração da Universidade Federal da Integração Latino-Americana (UNILA). Na UNILA coordena o Núcleo de Estudos para a Paz (NEP) e a Cátedra de Estudos para a Paz (CEPAZ). É, também, Professor Permanente no Programa de Pós-Graduação em Relações Internacionais da mesma Universidade (PPGRI-UNILA) e no Programa de Pós-Graduação em Ciência Política da Universidade Federal do Paraná (PPGCP-UFPR). 0 autor agradece 0 auxílio financeiro proporcionado às suas pesquisas pela Pró-Reitoria de Pesquisa e Pós-Graduação da UNILA sob os seguintes instrumentos financeiros: PRPPG No 109/2017, PRPPG No 58/2018, PRPPG № 110/2018, PRPPG

No 149/2018, PRPPG № 154/2018, PRPPG No 25/2019, PRPPG № 80/2019, PRPPG No 66/2020, PRPPG No 104/2020 e PRPPG No 105/2020. É autor de Peace as Government: The Will to Normalize Timor-Leste. London: Lexington Books, 2020. Contato: ramon.blanco@unila. edu.br. ORCID: https://orcid.org/00000003-0330-6235

\section{Abriendo la caja de herramientas de Foucault: delineando la gubernamentalidad global como un instrumento analítico para las Relaciones Internacionales}

Natali Hoff'

Ramon Blanco ${ }^{2}$

DOI: 10.5752/P.2317-773X.2021v9.n2.p34

Recebido em: 28 de abril de 2020

Aceito em: 23 de agosto de 2020

\section{RESUMO}

O presente artigo apresenta e delineia as contribuições do estudo sobre a governamentalidade global para a compreensão do ordenamento da política internacional ao dar ênfase para as relações existentes entre as racionalidades políticas e práticas de governo presentes no espaço internacional. Tendo em vista esse objetivo, essa pesquisa se desenvolve por meio da uma abordagem qualitativa por meio da Análise Bibliográfica, de modo que possa ser observado como a ideia de governamentalidade global possibilita um entendimento mais alargado sobre os processos, práticas, instituições e racionalidades políticas presentes no cenário internacional. Entende-se que a ideia de governamentalidade aplicada à análise do espaço internacional possibilita o seu estudo como um domínio socialmente incorporado, composto por práticas e racionalidades orientadas para objetivos específicos. Por conseguinte, a compreensão da organização da política internacional perpassa pela observação das mentalidades, das práticas e dos mecanismos ordenadores que a compõem e incidem sobre os seus atores.

Palavras-chave: Governamentalidade. Governamentalidade Global. Política Internacional.

\section{ABSTRACT}

This article presents and outlines the contributions of global governmentality studies to the understanding of the international political order by emphasizing 
the existing relations between political rationalities and government practices present in the international space. With this objective in mind, this research is developed through a qualitative approach, namely the Bibliographic Analysis, so that it can be observed how the idea of global governmentality enables a broader understanding of the processes, practices, institutions and political rationalities present on the international scene. It is understood that the idea of governmentality, when applied to the analysis of the international space, allows its study as a socially incorporated domain, composed of practices and rationalities oriented towards specific objectives. Consequently, the understanding of the organization of international politics permeates the observation of the mentalities, practices and ordering mechanisms that compose it and affect its actors.

Keywords: Governmentality. Global Governmentality. International Politics.

\section{RESUMEN}

Este artículo presenta y esboza las contribuciones del estudio sobre la gubernamentalidad global a la comprensión del ordenamiento de la política internacional, enfatizando las relaciones existentes entre las racionalidades políticas y las prácticas gubernamentales presentes en el espacio internacional. Con este objetivo en mente, esta investigación se desarrolla a través de un abordaje cualitativo a través del Análisis Bibliográfico, de manera que se pueda observar cómo la idea de gubernamentalidad global posibilita una comprensión más amplia de los procesos, prácticas, instituciones y racionalidades políticas presentes en la escena internacional. Se entiende que la idea de gubernamentalidad aplicada al análisis del espacio internacional permite su estudio como un dominio socialmente incorporado, compuesto por prácticas y racionalidades orientadas a objetivos específicos. En consecuencia, la comprensión de la organización de la política internacional pasa por la observación de las mentalidades, prácticas y mecanismos ordenadores que la componen y afectan a sus actores.

Palabras clave: Gubernamentalidad. Gubernamentalidad Global. Politica Internacional.

$$
\text { Introdução }
$$

O presente artigo analisa e delineia as potencialidades advindas da operacionalização da noção de governamentalidade global para uma melhor problematização, sobretudo crítica, da política internacional. Por conseguinte, o objetivo central desse trabalho é demonstrar como as contribuições teóricas e metodológicas do filósofo francês Michel Foucault, em especial o conceito de governamentalidade, possibilitam uma leitura mais apurada sobre as relações de poder e as redes de governança presentes na política internacional. O caráter crítico presente na obra de Foucault fez com que ele se tornasse uma das principais influências de uma abordagem pós-estruturalista nas Relações Internacionais ${ }^{3}$ (ASHLEY, 1987, 1990; BARTELSON, 1995; DERIAN, 1987; GEORGE, 1994; SHAPIRO, 1997, 1999; WALKER, 1993; WEBER, 1995) e para o questionamento dos pressupostos tradicionais da disciplina, sejam eles realistas ou liberais (PAOLINI, 1993, p. 99). De forma geral, os pressupostos tradicionais das Relações Internacionais se direcionam, por um lado, a analisar os atributos e os comportamentos dos Estados no sistema internacional (MORGENTHAU, 1946, p. 38) e, por outro lado, buscam compreender como a estrutura anárquica e competitiva desse sistema condiciona e limita a
3. Nesse trabalho será empregado 0 termo Relações Internacionais (com maiúscula) referindo-se a disciplina e 0 termo relações internacionais (com minúscula) para se direcionar ao conjunto de processos, interações e fenômenos observados no espaço internacional e estudados pela disciplina. 
4. Foucault compreende o governo como a 'conduta da conduta', uma vez que para ele o governo envolve a tentativa de moldar e conduzir os comportamentos dos indivíduos de acordo com um fim específico (FOUCAULT, 2008, p. 257). atuação dos Estados (WALTZ, 1979, p. 26). Dessa maneira, as discussões que compõem o mainstream da disciplina concentram-se, essencialmente, na investigação sobre as disputas pelo poder entre os Estados no sistema internacional e sobre a busca pela sobrevivência dentro desse sistema. Assim, o referencial teórico foucaultiano, de um modo geral, é frequentemente empregado nas Relações Internacionais para que se possa reinterpretar e ressignificar as principais questões presentes em discussões sobre os fenômenos internacionais.

Embora o pensamento de Michel Foucault tenha estado presente nas Relações Internacionais há algum tempo, a aplicação da noção de governamentalidade para a compreensão dos processos e das práticas políticas internacionais constitui-se em um desenvolvimento relativamente recente na área (JOSEPH, 2010, p. 224). O conceito de governamentalidade foi empregado por Foucault para descrever a o modo por meio do qual se pensa sobre o governo (FOUCAULT, 1991). Cabe ressaltar que o estudo sobre a governamentalidade explora o governo - entendido em termos foucaultianos não como algo assente nas estruturas institucionais, mas sim como 'a conduta da conduta'4 - para além de seus aspectos institucionais, e investiga como as dimensões discursivas do poder se manifestam nos imaginários políticos e nas racionalidades políticas que orientam a práxis (ZANOTTI, 2013, p. 238). Nesse sentido, a noção de governamentalidade remete imediatamente à ideia de racionalidade do governo e delineia as a lógica, os cálculos e a expertise envolvidos no ato de governar. Logo, a utilização desse conceito para o estudo dos fenômenos sociais (e internacionais) possibilita desnaturalizar as práticas políticas a partir de uma leitura crítica sobre os regimes de pensamento que as conformam.

Assim, a governamentalidade global estuda como se desenham as conexões entre os instrumentos de conhecimento e as práticas governamentais vigentes, bem como as consequências não intencionais desses esforços. Isso é possível porque os estudos sobre a conformação de uma governamentalidade focam na identificação das 'mentalidades' de governo presentes nas diferentes formas de se governar (NEUMANN; SENDING, 2010, p. 9). Dessa maneira, a governamentalidade conecta a prática do governo, de conduzir condutas, às formas sistemáticas de pensamento e conhecimento que o integram e o tornam operacional. Portanto, pensar sobre a governamentalidade em âmbito global permite, por exemplo, problematizar como as estruturas de 'governança', recorrentemente retratadas como 'democráticas' e benevolentes, podem conformar cristalizadas estruturas de poder. Nesse sentido, a governamentalidade não se refere apenas sobre como as instituições se comportam. Mais do que isso, constitui-se em uma abordagem preocupada com o arcabouço discursivo que dá sustentação ao exercício do governo no espaço internacional.

Desse modo, este artigo discute como a noção de governamentalidade, quando aplicada às Relações Internacionais, possibilita a investigação sobre as racionalidades políticas presentes no cenário internacional e sobre como estas moldam e ordenam as instituições, os atores e as práticas políticas internacionais de acordo com uma mentalidade de governo específica. Tendo isso em conta, o argumento central desse artigo é que a investigação sobre a conformação e sobre os efeitos da governamentalidade 
global é essencial para a compreensão mais refinada e acurada do ordenamento da política internacional contemporânea, sobretudo por possibilitar a análise dos regimes de pensamento que dão forma e sustentação a mesma. De modo a desenvolver a sua análise, o presente artigo está dividido em duas seções. Na primeira seção discute-se parte das contribuições do pensamento de Michel Foucault para as Relações Internacionais, evidenciando como as contribuições teóricas e conceituais permitem a ampliação das abordagens sobre os fenômenos internacionais. Na segunda seção, discorre-se especificamente sobre a noção de governamentalidade global, concedendo destaque a importância das análises sobre as racionalidades políticas para a compreensão do ordenamento da política internacional. Nesse sentido, delineia-se algumas das potencialidades da utilização do conceito de governamentalidade para se pensar a política internacional.

Michel Foucault e as Relações Internacionais: da crítica à pluralização de análises sobre o internacional

Para que se possa refletir sobre como a noção de governamentalidade global colabora para uma problematização mais adequada, e sobretudo crítica, da política internacional, é preciso, anteriormente, delinear como o pensamento de Michel Foucault contribui para a ampliação das leituras e abordagens teóricas das Relações Internacionais. Nesse sentido, essa seção apresenta e delineia algumas como as contribuições teóricas e conceituais de Foucault possibilitam, por um lado, uma compreensão mais apurada sobre as relações de poder no cenário internacional e, por outro lado, a problematização dos processos de produção e reprodução do conhecimento nas disciplina de Relações Internacionais. Desse modo, discute-se como as leituras foucaultianas das Relações Internacionais têm o potencial de iluminar as conexões existentes entre conhecimento e poder, ou seja, entre os conjuntos de verdades e as práticas políticas internacionais. Isso é possível porque a obra de Michel Foucault, em grande medida, está pautada na preocupação do autor com as relações existentes entre a produção dos saberes e o exercício cotidiano do poder. Tal preocupação, com os impactos práticos do conhecimento, fica evidente ao se refletir sobre os tradicionais métodos foucaultianos - o método arqueológico ${ }^{5}$ e o método genealógico ${ }^{6}$. Esses dois métodos, quando aplicados ao estudo das Relações Internacionais, abarcam um conjunto de técnicas analíticas que possibilitam o questionamento a respeito da constituição histórica dos conjuntos de verdades e de práticas no espaço internacional. Os métodos arqueológico e genealógico foucaultianos são baseados na análise das práticas discursivas e na problematização sobre o exercício do poder, de modo que passaram a ser incorporados como uma forma de se compreender o espaço internacional e a própria produção de conhecimento na área (SELBY, 2007, p. 236). O foco no exercício cotidiano do poder e na sua vinculação com a reprodução do conhecimento por meio da arqueologia e da genealogia ilumina o processo por meio do qual o internacional se conforma como um objeto de pensamento.

Dessa forma, o entendimento sobre a conformação de uma perspectiva analítica, preocupada com uma governamentalidade em âmbito
5. 0 método arqueológico foucaultiano busca investigar as práticas discursivas, procurando iluminar o processo por meio do qual se dá a constituição dos saberes (FOUCAULT, 2002, p. 239)

6. 0 método genealógico se refere a "constituição de um saber histórico sobre as lutas e a análise sobre a utilização deste saber nas técnicas de poder existentes na atualidade" (FOUCAULT, 1979, p. 171). 
7. A evolução das discussões sobre as teorias das Relações Internacionais pode ser descrita a partir de quatro grandes debates: i) o primeiro debate se deu entre realismo clássico e o liberalismo clássico entorno da discussão sobre guerra e paz; ii) o segundo debate foi entre tradicionalistas e behavioristas e versava sobre a metodologia da área; iii) o terceiro debate - também chamado de interparadigmático - englobou as dis cussões entre neorrealismo, neoliberalismo e neomarxismo e se direcionou a questionar as características do sistema internacional; iv) o quarto debate, com caráter metateórico, se deu entre racionalistas e reflexivistas e versa sobre 0 questionamento das bases ontológicas e epistemológicas da disciplina (MES SARI e NOGUEIRA, 2005). global, perpassa por entender como os conceitos foucaultianos fomentam o questionamento das bases ontológicas e epistemológicas das Relações Internacionais. A palavra ontologia tem sua origem das palavras gregas ontas (ente) e logos (teoria, discurso, palavra), significando, ao pé da letra, 'teoria dos entes' (CASTRO, 2008, p. 9). Assim, a ontologia se refere ao ramo da filosofia vinculado à metafísica e preocupado com as características mais gerais do 'ser' (CASTRO, 2008, p. 9). A ontologia de uma dada área do saber, ao estabelecer quais são as características mais básicas do ser, determina a maneira por meio da qual a realidade é apreendida e explicada. Por conseguinte, a ontologia precede a investigação científica, uma vez que envolve o modo como o mundo é assimilado pelo pesquisador e convertido em uma linguagem capaz de exprimir a sua complexidade (SILVA, 2005, p. 257). Os pressupostos ontológicos de uma disciplina estabelecem, para além dos atores, das coisas e dos fenômenos que poderão ser estudados, quais sãos os elementos que poderão ser ignorados e marginalizados em uma pesquisa científica. Portanto, a ontologia está vinculada à construção de um conjunto de concepções e verdades sobre o mundo, que ao hierarquizar os sujeitos e os fenômenos sociais a serem estudados, termina por legitimar as relações de poder.

No caso das Relações Internacional, as ontologias da disciplina delineiam quais são os 'atores titulares' da política internacional, ordenando-os de acordo com as suas interações no que se denomina como 'sistema internacional' (CASTRO, 2012, p. 428). Desde o início da disciplina, o Estado é classificado como o principal ator da relações internacionais, de modo que a compreensão das dinâmicas e dos fenômenos internacionais passa, diretamente, pela análise sobre como os Estados se comportam e interagem nos fenômenos internacionais. A teoria realista é a grande precursora desse tipo de entendimento e durante os três primeiros debates ${ }^{7}$ das Relações Internacionais não houve grandes questionamentos à centralidade do Estado na política Internacional. De uma forma geral, esses debates estavam mais preocupados em consolidar as Relações Internacionais enquanto campo científico e, para isso, divergiam quanto aos princípios ordenadores do comportamento dos Estados no sistema internacional.

Nesse sentido, ao se observar a conceitualização do Estado, nas teorias neorrealista e neoliberal, destacam-se algumas diferenças na forma como ele é abordado por cada uma delas. No entanto, ambas as correntes teóricas partem da ideia de que o Estado é o ator legítimo das relações internacionais e, portanto, merecedor de destaque nos estudos sobre a política internacional. Para o realismo o Estado configura-se em um ator homogêneo, racional e centrado na sua própria segurança e/ou sobrevivência diante do sistema internacional anárquico (JERVIS, 1998; MEARSHEIMER, 2001; WALTZ, 1979;). Assim, o Estado é entendido como um ator coeso e unitário, que se comporta de acordo com os desafios impostos pela estrutura internacional e com as suas próprias necessidades. Como a estrutura do sistema é anárquica, a principal necessidade do Estado é a garantia da sua própria sobrevivência diante das ameaças externas (WALTZ, 1979). A visão da teoria liberal sobre o Estado é um pouco diferente, uma vez que está muito mais preocupada com os reflexos das 
instituições e dos agentes domésticos para atuação deste no cenário internacional. Para os liberais, o comportamento do Estado nas relações internacionais é o resultado da disputa de interesses entre os grupos sociais que o compõem (MORAVCSIK, 2008). A abordagem liberal não entende o Estado como um ator homogêneo e unitário, prestando mais atenção à aspectos domésticos. Por conseguinte, para os liberais a atuação do Estado é central na política internacional, ao aglutinar os interesses de diferentes grupos sociais. Embora, cada vez mais novos atores ocupam uma posição de destaque na esfera internacional - como organizações internacionais, empresas transnacionais, a sociedade civil e até mesmo o indivíduo.

Tendo em conta o exposto acima, é possível observar que a maneira como se estuda e se problematiza 'o internacional' ainda está fortemente embasada em uma leitura estadocêntrica, que tende a invisibilizar o papel das ideias, das identidades, do conhecimento e dos atores considerados periféricos. Essa tendência é fortalecida pelo fato de que, tanto o neoliberalismo como o neorrealismo, estão conectados a um matriz epistemológica racionalista - que entende que a teorização das Relações Internacionais deve ser realizada a partir de um padrão universal de conhecimento científico (CASTRO, 2012, p. 297). Em consequência, as bases epistemológicas das teorias que compõem o mainstream das Relações Internacionais estão vinculadas ao que, Max Horkheimer e Theodor Adorno (1985), denominam de teorias tradicionais. Essas últimas defendem que as ciências humanas devem seguir os padrões analíticos das ciências naturais, concedendo prioridade à neutralidade científica em detrimento do questionamento sobre a complexidade do mundo social. Esse tipo de entendimento, em última instância, concede primazia às perspectivas teóricas do tipo "problem solving" (COX, 1981, p. 208), que defendem uma abordagem empirista do mundo cujo objetivo central é responder a um problema particular em um sistema social. Dentro desse enquadramento, o lugar da teoria é apenas descrever e explicar a realidade, não cabendo a ela uma função crítica e a transformadora.

Em contrapartida às abordagens racionalistas, a partir da década de 1980, teorias críticas passam a ganhar cada vez mais espaço na disciplina de Relações Internacionais - como as abordagens construtivistas, da teoria crítica, pós-estruturalistas, de gênero e o pensamento decolonial e pós-colonial. Essas teorias críticas, se direcionam a questionar as fundações epistemológicas e ontológicas das Relações Internacionais. As suas leituras sobre o 'internacional' evidenciam os efeitos das relações de poder para a produção do conhecimento na área, bem como os impactos das assimetrias políticas e econômicas para o funcionamento da política internacional. Em essência, elas questionam as estruturas de poder desde múltiplas perspectivas. O referencial teórico foucaultiano é, justamente, empregado nas Relações Internacionais com esse sentido crítico e questionador. A partir das contribuições de Foucault é possível iluminar os processos de formação e de consolidação dos padrões discursivos que moldam e orientam o exercício do poder na esfera internacional - incluindo desde a problematização sobre os conceitos e teorias das Relações Internacionais à análises sobre a prática diplomática, a atuação das Organizações Internacionais, o 
8. Para ler mais sobre esse tipo de abordagem, pode-se ver: Waltz, Kenneth. (1979) Theory of International Politics, New York, McGraw-Hill. direito internacional e a interação entre os Estados (JOSEPH, 2010, p. 2). Assim, o caráter crítico do trabalho desenvolvido por Foucault permite que a aplicação das suas ideias nas Relações Internacionais se distancie das concepções dominantes da área, iluminando padrões de comportamento usualmente marginalizados pelas análises clássicas da disciplina.

Nesse sentido, observando atentamente, é bastante evidente que o elemento que mais aproxima Foucault das Relações Internacionais é a sua concepção de poder dissonante das leituras mais tradicionais, sobretudo na área, sobre a questão. Foucault compreende o poder a partir de uma leitura positiva e produtiva do seu exercício, focando-se assim nas condutas e comportamentos produzidos, sobretudo no que toca à construção de subjetividades, do mesmo. Esta leitura afasta-se das visões convencionais da teoria política, normalmente negativa e repressiva, que frequentemente associam o poder às ideias de "posse" e de "força". Não por acaso, nessas abordagens tradicionais, o poder costuma ser: (1) entendido como algo que pode ser possuído por um agente; e (2) utilizado para a impor vontade de um agente poderoso a outro agente desprovido de poder (HAYWARD, 2000 , p. 38). Não raramente, é esse entendimento mais tradicional acerca do poder que normalmente possui o privilégio analítico na área das Relações Internacionais ${ }^{8}$. Consequentemente, a política internacional é frequentemente problematizada a partir de conceitos que versam sobre a consolidação de um poder material dos Estados (militar e econômico) e sobre a delimitação e perseguição dos interesses desses em um ambiente anárquico (SELBY, 2007, p. 331). Este tipo de leitura certamente não está de todo incorreta. Contudo, não deixa de ser incompleta, uma vez que é completamente cega à uma parte significativa da realidade internacional.

Uma problematização a partir de uma leitura foucaultiana permite uma compreensão mais adequada, e consequentemente mais curada, da realidade internacional pois entende o poder, e a sua operacionalização na política internacional, de um modo mais alargado. Em contrapartida, para Foucault "o poder não deve ser conhecido como algo detido por uma classe (os dominantes) que o teria conquistado", uma vez que esse tipo de entendimento conduz a conclusão de que "as relações de poder presumem um enfrentamento perpétuo" (MAIA, 1995, p. 87). Foucault, por sua vez, se opõe às concepções de que o poder se constitui na capacidade que determinado agente possui para mobilizar e aglutinar forças - sejam elas econômicas, sociais ou políticas - para obter um resultado esperado em detrimento da liberdade de escolha do outro (BLACKBURN, 1997, p. 301). Esse tipo de visão tem o poder como algo negativo e repressivo, compreendendo-o essencialmente como uma ação que proíbe, censura, repreende e coage os indivíduos (MAIA, 1995, p. 85). Foucault, por sua vez, deixa de lado essa hipótese repressiva do poder (POGREBINSCHI, 2004, p.186). Em consequência disso, dentro do enquadramento foucaultiano, o poder não deve ser entendido apenas como uma força que proíbe, reprime e coage os indivíduos. Muito pelo contrário, a definição foucaultiana entende que "o que faz com que o poder se mantenha e que seja aceito é simplesmente que ele não pesa só como a força que diz não, mas que de fato ele permeia, produz coisas, induz ao prazer, forma saber e produz discurso" (FOUCAULT, 1979, p. 8). O exercício do poder acaba então por 
se converter em uma força necessária, produtiva e constitutiva na sociedade (FOUCAULT, 1975, p. 161). De forma mais específica, Foucault "problematiza o poder como um relacionamento onde um tenta produzir, direcionar ou determinar os comportamentos de outros" (BLANCO, 2017, p.90). Para Foucault o poder não se configura em um atributo unicamente material, mas apresenta-se em termos de relação (DELEUZE, 2006, p. 27).

Essa preocupação a respeito de como se dá exercício do poder, leva ao desenvolvimento da concepção foucaultiana de tecnologia de poder como a forma de se apreender as relações cotidianas por meio das quais o poder é exercido (FOUCAULT, 1980, p. 122). Nesse sentido, o termo "tecnologia" configura-se mais como uma expressão, do que como um conceito propriamente dito (BLANCO, 2013, p. 53). Diferentemente da compreensão mais comum de tecnologia, na abordagem foucaultiana, se refere a diferentes formas de conhecimento vinculadas a uma variedade de dispositivos mecânicos e a uma variedade de pequenas técnicas orientadas para produzir resultados práticos (ROSE, 2004, p. 52). As tecnologias de poder, então, seriam responsáveis por conectar diversos tipos de conhecimentos, capacidades e métodos de julgamento, direcionando-os ao cumprimento de fins específicos (FOUCAULT, 1980, p. 122). Logo, as tecnologias de poder são aquelas tecnologias que buscam a formação de condutas, objetivando, em última análise, produzir efeitos desejados e evitar efeitos indesejados (BLANCO, 2013, p. 52). É importante destacar que as tecnologias de poder não são socialmente ou politicamente neutras, uma vez que alteram profundamente o ordenamento das coisas (KELLY, 2009, p. 44), uma vez que operam de modo a produzir modificações no comportamento e na disposição das coisas em uma sociedade. Para Foucault (1987, p. 111) a disciplina ${ }^{9}$, a biopolítica ${ }^{10}$ e o governo são tecnologias de poder utilizadas na modernidade para moldar e conduzir os comportamentos dos indivíduos de acordo com os fins esperados. Essas três tecnologias de poder, visualizadas por Foucault, não substituem umas às outras. Muito pelo contrário, elas operam em diferentes níveis e escalas e são operadas através de diferentes instrumentos (BLANCO, 2013, p. 55).

Tendo em contato a vasta obra desenvolvida por Michel Foucault ao longo de sua vida, esse artigo dará centralidade à compreensão de uma tecnologia de poder específica - o governo - em decorrência da sua importância para o entendimento acerca da noção de governamentalidade. Para Foucault, a ideia de governo não está, somente relacionada com a gestão formal do Estado, ou mesmo, com a soberania de um corpo territorial que reclama o monopólio da força (DEAN, 2010, p. 16). Pelo contrário, Foucault compreende o governo como a "conduta da conduta" (FOUCAULT, 2008, p. 257). Assim, o entendimento de governo foucaultiano explora os dois sentidos da palavra conduta. Dentro dessa concepção, conduta é, por um lado, entendida a partir do significado do verbo conduzir, indicando a ideia de guiar ou dirigir. Por outro lado, o termo também é entendido a partir do substantivo conduta, referindo-se às ações e aos comportamentos humanos (FOUCAULT, 2008, p. 258). Por conseguinte, o governo como "conduta da conduta" implica em qualquer tentativa deliberada de moldar os comportamentos dos indivíduos de acordo com conjuntos particulares de normas e para uma variedade de fins" (DEAN,
9. A disciplina é uma tecnologia de poder exercida diretamente sobre os indivíduos e é caracterizada por estabelecer um sistema de recompensas e punições, buscando corrigir os comportamentos daqueles indivíduos percebidos como desviantes. Nesse sentido, Foucault diz que podemos chamar de disciplina aos "métodos que permitem o controle minucioso das operações do corpo, que realizam a sujeição constante de suas forças e lhes impõem uma relação de docilidade-utilidade" (FOUCAULT, 1987, p. 25).

10. A biopolítica é uma política que trata da gestão do processo da vida dos indivíduos que compõem a população. Essencialmente, a biopolítica objetiva a regulação e a administração da população, buscando moldar e orienta as condutas dos indivíduos que fazem parte da população (FOUCAULT, 2008, p.327). A biopolítica, se preocupa com a "gestão dos fenômenos que caracterizam os grupos de seres humanos vivos" (BLANCO, 2017, p.93). 
11. Para mais acerca das problematizações de Foucault acerca da política internacional, ver (DEAN, 2010, Capítulo
2010, p. 18). Ele engloba, portanto, um número significativo de agentes e fatores que vão muito além da esfera formal do Estado, envolvendo as relações e interações nas famílias, nas empresas, nas escolas e em outras instituições sociais (LEMKE, 2002, p.191).

Dessa maneira, não é nenhuma surpresa que as temáticas e abordagens mais dominantes nas RI sejam de algum modo dissonantes das preocupações contidas no arcabouço analítico foucaultiano (HUTCHINGS, 1997, p. 102). Mais do que isso, a própria política internacional acaba por não ser um dos fenômenos mais recorrentemente abordados e problematizados na obra foucaultiana" ${ }^{11}$ Todavia, como Foucault se dedicou a entender os instrumentos de poder presentes nas sociedades contemporâneas, bem como as suas relações com as racionalidades e as práticas liberais (SELBY, 2007, p. 331), é bastante possível se apoiar em sua obra para refletir sobre as relações de poder presentes no cenário internacional. Essa, inclusive, era a intenção do mesmo ao mencionar que sua reflexão teórica e conceitual deveria ser apropriada por pesquisadoras de áreas distintas. Isso acontece porque a conceitualização contida na obra de Foucault pode ser entendida como uma "caixa de ferramentas" (FOUCAULT, 1994, p. 523-524). Nesse mesmo sentido, Foucault defende que os seus livros e, principalmente, os seus conceitos sejam considerados e utilizados como essa caixa de ferramentas, a partir da qual pesquisadores de diferentes áreas do conhecimento possam se apropriar dos seus conceitos e instrumentos de análise para compreender diversos fenômenos da vida social (NEAL, 2009, p. 162).

Nesse sentido, é notório que o pensamento de Foucault acaba por oferecer uma série de instrumentos analíticos e metodológicos que possibilitam a visualização e a problematização das relações de poder e das práticas sócio-política na atualidade. Consequentemente, o pensamento do mesmo acaba sendo operacionalizado por teóricos e analistas internacionais para a investigação de fenômenos e problemáticas distintas. Em essência, os conceitos e as técnicas de análises foucaultianos acabam sendo reapropriados por abordagens das Relações Internacionais com o objetivo de explicar e compreender uma ampla diversidade de questões e problemas relacionados com as práticas cotidianas de poder no espaço internacional. É possível observar que o referencial foucaultiano nas Relações Internacionais está mais frequentemente associado a três propósitos analíticos principais (SELBY, 2007, p. 326-335). O primeiro propósito analítico constitui-se no desenvolvimento de uma abordagem crítica às teorias dominantes da área, promovendo a desconstrução dos pressupostos teóricos e conceituais do mainstream da disciplina. As críticas se direcionam com maior frequência à corrente realista e à sua ontologia estadocêntrica e utilitarista para as relações internacionais (SELBY, 2007, p. 227). Nesse enquadramento, questionam-se os processos de significação e sujeição que compõem a construção narrativa dos conceitos fundacionais da área como o Estado, a soberania e o sistema internacional - e a sua relação com a ordenação do mundo material (ASHLEY, 1990, p. 386; BARTELSON, 1995, p. 8; GEORGE, 1994, p. 191; WALKER, 1993, p. 23). Por conseguinte, o principal objetivo é evidenciar como a visão realista estadocêntrica acaba por condicionar práticas e estruturas centralizadas na figura do Estado 
e das suas necessidades na política internacional (WEBER, 1995, p. 123). O segundo propósito analítico, por sua vez, concentra-se na elaboração de análises e conceitos sobre os discursos e sobre as práticas políticas presentes no meio internacional - dentro desse enquadramento, a noção de governamentalidade ocupa um papel central ao possibilitar a análise sobre a conformação de técnicas de governamento no espaço internacional. O terceiro propósito analítico recorrentemente associado ao pensamento foucaultiano envolve a criação de novos instrumentos e técnicas de análise para se compreender a ordem liberal global contemporânea. Esses propósitos evidenciam que o arcabouço foucaultiano é empregado não apenas para se questionar e se problematizar o referencial teórico dominante nas Relações Internacionais, como também para estimular novas formas de se pensar e analisar criticamente os fenômenos internacionais.

Nessa seção delineou-se algumas das contribuições do referencial foucaultiano para as reflexões sobre o espaço internacional. Pode-se observar que as ideias de Foucault são importantes para a ascensão de perspectivas críticas e questionadoras, tanto sobre os fenômenos internacionais, como também sobre a produção teórica na área. As concepções de Foucault a respeito do poder, do biopoder e das tecnologias de poder acabaram por se converter em importantes instrumentos analíticos para a problematização das relações internacionais, uma vez que incentivam que a esfera internacional seja compreendida e problematizada como um domínio composto por práticas e estratégias políticas compartilhadas pelos diversos agentes que o compõem. Tais prática e estratégias estão intrinsecamente vinculadas aos conhecimentos e às narrativas sobre o modus operandi adequado na política internacional. Por conseguinte, não é nenhum exagero afirmar que o potencial da aplicação do pensamento foucaultiano às Relações Internacionais esteja na intersecção estabelecida entre poder e conhecimento na obra do mesmo. Assim, mais do que possibilitar análises críticas sobre os pressupostos dominantes das Relações Internacionais, os conceitos foucaultianos permitem investigar sobre como as práticas estabelecidas na esfera internacional se configuram e se sustentam a partir dos quadros discursivos e teóricos presentes nesse espaço.

A governamentalidade global: da episteme às práticas de governo em âmbito internacional

Tendo em conta as potencialidades do conceito de governamentalidade para o estudo das relações internacionais, nessa seção apresentaremos como a noção de governamentalidade global colabora para a análise da política internacional. Desse modo, objetiva-se, incialmente, responder ao questionamento sobre o que significa a noção de governamentalidade e por qual razão esse conceito passou a ganhar centralidade nas ciências sociais, de forma geral, e nas Relações Internacionais, especificamente. Por conseguinte, mesmo com o desenvolvimento tardio dentro da obra foucaultiana, que se deu somente a partir das suas Palestras no Collège de France entre os anos de 1975 a 1979, o conceito de governamentalidade ganhou considerável força como uma ferramenta analítica para explorar criticamente técnicas de governo dentro e fora do Estado (ZANOTTI, 
2013, p. 237). Uma parte significativa do potencial analítico da noção de governamentalidade, sobretudo quando se trata da análise das relações internacionais, reside no fato de que a governamentalidade possibilita uma problematização mais profunda e alargada do exercício do poder, e da racionalização desse exercício, para além do Estado (MILLER; ROSE, 1992, p. 2; ZANOTTI, 2013, p. 237). Uma vez que para o Foucault não seria possível estudar as tecnologias do poder sem uma análise das racionalidades políticas que as moldam e sustentam, o termo governamentalidade busca, mais precisamente, dar visibilidade, por meio da ligação semântica entre as palavras governo e mentalidade, aos modos de pensamento e racionalidades envolvidas no exercício do governo (GORDON, 1991, p. 1). Dessa forma, a noção de governamentalidade, quando aplicada às relações internacionais, permite que a pesquisadora questione, por uma lado, como se conformam os centros de produção conhecimento na esfera internacional, e por outro lado, como esse conhecimento termina por modificar e conduzir as condutas dos mais diferentes atores internacionais.

Esse tipo de problematização é possível, porque o governo, dentro desse enquadramento, é entendido como uma tentativa de moldar e conduzir os comportamentos dos indivíduos de acordo com fins específicos. A governamentalidade, por sua vez, diz respeito aos elementos racionais que compõem o governo, ou seja, se refere àquilo que pode ser conhecido sobre o governo. Desse modo, é a da noção de governamentalidade que se pode estudar a formação das práticas organizadas de pensamento por meio das quais se governa e se é governado (DEAN, 2010, p.28). Desse modo, a governamentalidade é empregada por como uma ferramenta analítica destinada a estudar as transformações que possibilitaram as modalidades contemporâneas do governo à distância (ZANOTTI, 2013, p. 238). Mais precisamente, Michel Foucault define, em sua obra, governamentalidade como:

[...] um conjunto formado por instituições, procedimentos, análises e reflexões, cálculos e táticas que permitem o exercício desse poder específico, mas complexo, que tem a população como seu alvo, a economia política como sua forma de conhecimento e o aparato de segurança como seu instrumento técnico essencial (FOUCAULT, 2007, p. 108).

Por esse ângulo, a problematização deve estar preocupada com os meios de cálculo que possibilitam o exercício do governo, o tipo de autoridade que se consolida e com as formas de conhecimento envolvidas em todo esse processo (GORDON, 1991, p. 10). Assim, ao transpor esse conceito para as Relações Internacionais, é preciso problematizar os mecanismos e racionalidades que possibilitam a operacionalização do governo no âmbito da política internacional. Isso é possível porque a ideia contida no conceito de governamentalidade permite a investigação sobre as práticas utilizadas para se governar, concomitantemente à observação das racionalidades políticas que tornam possível se governar de tal maneira (JOSEPH, 2010, p. 243). Consequentemente, a ideia de governamentalidade, nesse sentido, não é apenas sobre como as instituições se comportam, mas também sobre como se consolidam as práticas discursivas que dão forma e tornam o governo viável (LEMKE, 2007, p. 47). Dessa maneira, a governamentalidade vai além da análise do exercício direto do poder es- 
tatal, buscando observar como as sociedades (e os próprios Estados) produzem métodos mais sutis de poder, que são exercidos por meio de uma rede de instituições, práticas, procedimentos, técnicas e racionalidades que atuam para regular a conduta social, inclusive no âmbito das relações internacionais. Essa potencialidade analítica da governamentalidade é a que concede o seu caráter inovador e crítico para a análise das relações internacionais, uma vez que objetos tradicionais da disciplina, como a atuação do Estado e o funcionamento das redes de governança internacionais, podem ser analisados em conjunto com elementos mais subjetivos, tal qual as ideias, o conhecimento e os discursos. Em decorrência, é possível visualizar relações de poder mais sutis e, geralmente, traduzidas em termos de condicionalidade, identidade e aprendizado coletivo.

Todavia, ao se pensar sobre a governamentalidade, especialmente na esfera internacional, questiona-se sobre como é possível apreender essas relações mais sutis de poder. Certamente, esse não é um caminho analítico simples e demanda dos pesquisadores uma observação cuidadosa sobre os aspectos ideacionais, discursivos e práticos da política internacional. Com o objetivo de sistematizar o estudo sobre a governamentalidade, Mitchell Dean (2010, p. 30) afirma que é preciso partir de uma analítica $^{12}$ do governo, uma vez que esse tipo de análise busca examinar não apenas o modo por meio do qual as coisas são feitas, como também quais as formas de raciocínio envolvidos. Em função disso, percebe-se que a analítica de governo examina, essencialmente, a modo por meio do qual os regimes de práticas surgem e se consolidam. Os regimes de práticas são entendidos como conjuntos, mais ou menos organizados, formados por modos de se fazer as coisas (DEAN, 2010, p. 31). Assim, quando se fala em regimes de práticas, por um lado, refere-se aos modos de fazer as coisas em uma sociedade e, por outro lado, inclui-se as diferentes mentalidades vinculadas ao exercício dessas práticas, tornando-os objeto do conhecimento e sujeitando-os a problematizações. Por conseguinte, para Dean (2010, p. 32), há uma dependência entre os regimes de práticas e a consolidação de conhecimentos e cálculos específicos sobre o governo.

Partindo da analítica de governo proposta por Dean, observa-se que uma análise sobre a governamentalidade, em especial em âmbito global, demanda que cinco dimensões que são, por um lado relativamente autônomas, e por outro, condicionantes uma das outras, sejam consideradas (BLANCO, 2012, 2020; DEAN, 2010, p. 33). Essas dimensões são: visibilidades/percepções, técnicas/práticas, conhecimentos, identificações e a atuação dos especialistas (BLANCO, 2013, p. 68). A primeira dimensão diz respeito aos elementos ao quais são dados visibilidade em um conjunto específico de práticas. Logo, quando se fala em um conjunto de elementos visíveis, torna-se inevitável indagar sobre quais os propósitos de se iluminar um determinado conjunto de práticas e verdades estabelecidas em uma ordem social particular (DEAN, 2010, p. 41). Para ser mais preciso, a dimensão da visibilidade indica a necessidade de analisar como quem e o que estão sendo governados são tornados visíveis (BLANCO, 2013, p. 68). Isso pode incluir, por exemplo, desenhos arquitetônicos, fluxogramas, mapas, gráficos e estatísticas. A segunda dimensão refere-se aos aspectos técnicos do governo utilizados para realizar a modelagem
12. Uma "analítica" é um tipo de estudo que está preocupado com as condições específicas a partir das quais os fenômenos surgem, se consolidam e se modificam (DEAN, 2010, p. 33) 
e o direcionamento das condutas. Essa dimensão, então, foca nas táticas, mecanismos, procedimentos e vocabulários por meios dos quais a autoridade é constituída em uma sociedade (DEAN, 2010, p. 42). A terceira dimensão constitui-se na "episteme do governo" e está relacionada com as formas de conhecimento que sustentam e informam a atividade de governar. Ela abrange os meios de cálculo, as teorias e conceitos que dão sustentação a dado regime de prática (DEAN, 2010, p. 44). Por fim, a quarta e última dimensão alude às identidades, coletivas ou individuais, por meio das quais o governo opera e a que práticas e programas de governo tentam formar (DEAN, 2010, p. 43). Essa dimensão abriga os questionamentos sobre qual o tipo de conduta que se espera moldar e quais os objetivos com essas modificações. Ramon Blanco (2020, p.17) adiciona uma quinta dimensão que deve ser considerada em uma analítica de governo, sobretudo no que tange as análises sobre os regimes de práticas internacionais, o papel dos especialistas ou peritos. Para Blanco (2020), os especialistas ou peritos ocupam uma posição privilegiada para guiar e orientar as condutas e, consequentemente, as práticas de governo na política internacional.

Nesse sentido, a governamentalidade ao conduzir a pesquisadora a questionar quem governa, o que se governa e quem é governado, e os modos de se pensar, calcular e operacionalizar este governo, desnaturaliza as racionalidades políticas que sustentam e moldam a política internacional. Isso ocorre porque, Foucault (1991, p.102) entende que com a governamentalidade podem-se identificar racionalizações políticas específicas, emergindo em locais precisos e em momentos históricos específicos, sendo sustentadas por sistemas de pensamento coerentes e sistemáticos (ROSE, 2004, p. 24), e determinadas racionalidades. Mas afinal, o que vem a ser uma racionalidade política e como a sua identificação pode fomentar uma compreensão mais alargada da política internacional? Respondendo a primeira parte da pergunta, destaca-se que, dentro de um enquadramento foucaultiano, racionalidade é qualquer tipo de raciocínio ou jeito de se pensar, calcular e responder a um problema que é mais ou menos sistemático e que acaba por dar forma a corpos formais de conhecimento e expertise (ROSE, 2004, p. 24). Nesse sentido, as racionalidades políticas possuem um caráter epistemológico e são articuladas em vias de compreender as instâncias sociais a serem governadas (ROSE, 2004, p. 26). Para responder a segunda parte da pergunta, é preciso destacar que o espaço internacional, assim como o doméstico, é moldado de acordo com o surgimento e a consolidação de racionalidades políticas específicas. Essas racionalidades influenciam e determinam, não apenas as estruturas de poder no cenário internacional, como a conduta dos atores. Assim, a análise sobre como as racionalidades políticas produzem efeitos práticos nas relações internacionais torna possível a visualização e a problematização de uma governamentalidade global.

Antes de se avançar no delineamento mais aprofundado acerca da noção de governamentalidade global, é importante distingui-la de um termo muitas vezes utilizado, erroneamente, enquanto seu sinônimo - governança global. A governança pode ser definida como "atividades apoiadas em objetivos comuns, que podem ou não derivar de responsa- 
bilidades legais e formalmente prescritas e não dependem, necessariamente, do poder de polícia para que sejam aceitas e vençam resistências" (ROSENAU, 2000, p. 15). Assim, a ideia de governança pode direcionar a reflexão ao pensar sobre o processo contínuo por meio do qual conflitos, divergências e interesses comuns são acomodados em redes de governança. Isso inclui instituições formais e regimes fortalecidos para fazer valer compromissos, assim como arranjos governativos informais direcionados a assuntos específicos (COMISSION ON GLOBAL GOVERNANCE, 1995, p.4). Por conseguinte, a governança global assume as práticas e racionalidades dominantes no espaço internacional como um dado adquirido, se direcionando apenas a compreender o seu funcionamento e sem necessariamente questionar as estruturas de poder subjacentes ao mesmo. Diferentemente, a noção de governamentalidade conduz a pesquisadora a problematizar como as racionalidades de governo estão diretamente conectadas com as práticas políticas internacionais. Assim, a pensar sobre uma governamentalidade global é, justamente, desnaturalizar as redes e as normas de governança que são a marca de um tempo específico.

A operacionalização da noção de governamentalidade para a análise da política internacional, ao contrário da ideia de governança, permite que esta seja estudada como um domínio essencialmente social, composto por práticas e racionalidades políticas orientadas para objetivos específicos (NEUMANN; SENDING; 2006, p. 678). Consequentemente, a compreensão da organização da política internacional, perpassa pela observação das mentalidades, das práticas e dos mecanismos ordenadores que a compõem e incidem sobre os seus atores. Assim, para compreender como a governamentalidade é operada na política internacional, é necessário que se faça um delineamento detalhado dos diversos processos, procedimentos, relações, conhecimentos e normas identificados com o governo, observando quando e como eles se transformam em práticas estáveis, replicáveis e até mesmo institucionalizadas (NEUMANN; SENDING, 2006, p. 678). A partir disso é possível problematizar os conjuntos de racionalizações, teorizações e conhecimento técnicos ligados aos meios estabelecidos para moldar e reformular as condutas, as práticas e as instituições presentes na política internacional (ROSE, 2004, p. 20). Dessa forma, Wendy Larner e William Walters $(2004$, p. 2) se referem à governamentalidade global não apenas para um fenômeno do nosso tempo, mas sobretudo, como denominação para o conjunto de estudos que problematiza a constituição de uma governança dos espaços localizados acima, através e além do Estado. A governamentalidade global abarca, então, as contribuições analíticas preocupadas em dar inteligibilidade ao governo de domínios que possuem um caráter internacional, como, por exemplo, o controle dos fluxos de migração internacionais ou a formação de entidades como a União Europeia (DEAN, 2010, p. 229).

Dentro das diferentes problematizações acerca da governamentalidade global, é importante perceber o destaque dado ao neoliberalismo possui dentro das mesmas. Isso ocorre porque o neoliberalismo é visto como uma maneira particular de construir a vida social através da introdução da economia política nas práticas sociais e políticas (JOSEPH, 2010, p. 32), sobretudo no âmbito do cenário internacional contemporâ- 
neo. Isso significa que o neoliberalismo é entendido enquanto uma forma de regulação social que introduz uma racionalidade particular derivada do empreendimento individual e uma crença de que as coisas funcionam melhor quando a governança encoraja a livre conduta (JOSEPH, 2010, p. 32). Isto decorre do entendimento de que o liberalismo não deve ser entendido como uma ideologia ou como uma maneira por meio da qual a sociedade 'representa a si mesma', mas como uma prática, uma maneira de se 'fazer as coisas' (FOUCAULT, 2008, p. 318) - uma racionalidade de governo. Nesse sentido, analisar a política internacional a partir da governamentalidade implica em compreendê-la como uma estrutura (definida por relações de poder) que gera práticas distintas e cambiáveis de domínio político (definido como racionalidade governamental) (NEUMANN; SENDING, 2007, p. 700). Assim, a governamentalidade pode nos ajudar a entender como a política internacional funciona, ao iluminar como diferentes racionalidades políticas são definidas por certas regras, práticas e técnicas, e como tais racionalidades geram orientações de ação e comportamento de atores específicos (NEUMANN; SENDING, 2007, p. 668)

Nesse contexto, relativamente ao cenário internacional atual, seria possível perceber a densa rede de normas e regras neoliberais buscando conduzir os comportamentos não apenas dos Estados, mas de outras organizações políticas - como ONGs, por exemplo - e também dos indivíduos (JOSEPH, 2010, p. 233). Esse tipo de concepção permite perceber a política internacional na qual as instituições e os países do centro do sistema internacional buscam moldar o comportamento de países da periferia do mesmo. Essa disposição do poder pode ser observada, por exemplo, por meio da postura adotada por organizações como o Banco Mundial e o FMI buscando por conduzir a conduta de países periféricos segundo determinados parâmetros condizentes à governamentalidade global. Dentre estes, pode-se citar, por exemplo: (1) a ênfase à necessidade de implementação, por parte dos países receptores de suas práticas, de políticas de privatização; (2) a abertura dos mercados à livre concorrência; e (3) a redução de envolvimento direto do Estado nos processos econômicos; para mencionar apenas alguns (JOSEPH, 2010, p. 133). Laura Zanotti (2005, p. 480) compreende essa dinâmica como uma governamentalidade operacionalizada a partir ideia de "boa governança" que busca conduzir a conduta de um Estado tanto no âmbito da política internacional, como no âmbito doméstico do mesmo. Tendo isso em conta, é possível perceber o como o governo, entendido enquanto conduta da conduta, é racionalizado na esfera internacional (JOSEPH, 2010, p. 133).

A discussão entorno da ideia de "boa governança" é central para compreender os arranjos e as práticas políticas internacionais dominantes no cenário internacional desde o fim da Guerra Fria. O fim da disputa entre as duas "visões de mundo" antagônicas, o socialismo da União Soviética e o capitalismo dos Estados Unidos, fez emergir no cenário político internacional, do início dos anos 1990, uma espécie de "triunfalismo democrático-liberal”. Em tal contexto, Francis Fukuyama (1992, p. 13) escreve "O Fim da História e o Último Homem”, no qual defende que a derrocada da União Soviética representava o fim das disputas ideológicas e consolidava a hegemonia dos modelos políticos e econômicos liberais. Nesse cenário 
de otimismo liberal, se fortalece entre analistas e polymakers das relações internacionais a ideia de segurança, desenvolvimento e democracia são conceitos indissociáveis (BLANCO, 2020; ZANOTTI, 2005). Assim, observa-se um movimento de migração dos discursos sobre os caminhos possíveis para se alcançar a paz e o desenvolvimento dos fatores econômicos e/ou da estrutura do sistema internacional para a qualidade das instituições estatais (ZANOTTI, 2005, p. 461). Esses discursos imediatamente passaram a ter efeitos práticos, sobretudo na esfera de segurança internacional. Os esforços de construção da paz que, durante a Guerra Fria, se caracterizavam pela neutralidade dos interventores e pela preocupação com o cessar fogo e com a assinatura dos acordos de paz; a partir dos anos 1990 convertem-se em um empreendimento mais alargado, direcionados a reconstrução dos Estado nos moldes liberais. Por conseguinte, a paz, nesse cenário, é percebida como produto das instituições democráticas e liberais. Ramon Blanco (2017) aponta que essas intervenções, em última instância, convertem-se em tentativas de normalização dos Estados pós-conflitos. Elas podem ser consideradas como processos de normalização já que modificam as estruturas do Estado e a sua relação com a sua população, com o objetivo de transformá-los em algo mais parecido com o que se entende por normal - as democracias liberais ${ }^{13}$.

Tendo em conta a discussão acima, Mark Duffield (2005, p. 2) problematiza a centralidade da racionalidade política libera $1^{14}$ para as práticas internacionais de construção da paz. Para Duffield, atualmente é crescente a percepção de que situações que antes eram consideradas problemas internos dos países - como os conflitos civis, o crescimento acelerado da população urbana acompanhado do aumento da pobreza e da desigualdade e o aumento da violência em situações de não guerra - agora se constituem em ameaças à estabilidade internacional (DUFFIELD, 2005, p. 3). Dentro dessa conjuntura, a promoção da segurança no mundo engloba a criação de mecanismos que incidem sobre os mais diversos aspectos da vida social e política dos Estados, como a natalidade da população, a expectativa de vida em um local, a mobilidade interna e internacional, a desigualdade entre classes, gêneros e raças, o nível de escolaridade de uma população e o combate ao crime e à violência. Em consequência, a segurança transforma-se em uma problemática liberal (DUFFIELD, 2005, p. 4) e fazer parte de uma governamentalidade que não está mais apenas restrita a países em ou pós-conflito.

A segurança enquanto um problema de ordem liberal tende a ampliar as formas de intervenção internacionais para a construção da paz e para garantia da segurança, bem como as localidades passíveis dessas intervenções e os instrumentos utilizados nesses processos. A ideia de boa governança se torna central por permitir que o governo internacional possa operar tanto diretamente, como a distância através de mecanismos indiretos de poder e técnicas de governo mais sutis. Destaca-se aqui que, para Foucault $(2008$, p. 63), a "liberdade não é outra coisa [...] do que a relação entre governantes e governados". Desse modo, a grande diferenciação das formas liberais de governo é que "elas substituíram as regulamentações externas pelas produções internas", de modo que função primordial do liberalismo é promover as condições nas quais os indi-
13. Caso tenha interesse em compreender de forma mais aprofundada como os processos de reconstrução de Estados podem ser compreendidos como tentativas de normalização, ler: Blanco, 2020

14. 0 liberalismo, dentro de uma abordagem foucaultiana deve ser entendido como uma prática, uma maneira de se 'fazer as coisas' (FOUCAULT, 2008, p. 318) - uma racionalidade de governo. 
víduos podem exercer essa liberdade (LEMKE, 2014, p. 111). Assim, se por um lado, o governo liberal consome a liberdade que ele mesmo produz, por outro lado, o liberalismo é responsável por em perigo essa liberdade (LEMKE, 2014, p. 112). Em consequência, o liberalismo produz liberdades que são permanentemente ameaçadas (LEMKE, 2014, p. 113). Para Foucault, esse paradoxo, revela que para que a liberdade liberal possa existir, ela precisará sempre da intervenção de um poder "estabilizador" e "protetor" (FOUCAULT, 2008, p. 64). Por conseguinte, ao se dedicar uma leitura mais atenta à governamentalidade liberal, pode-se observar que ela, inevitavelmente, produzira dispositivos de governo destinados a controlar ainda que a distância - a conduta dos atores interna e internacionalmente.

Laura Zanotti (2013) destaca que existem duas vertentes de pesquisas na área das Relações Internacionais direcionadas a problematizar como a governamentalidade impacta as dinâmicas internacionais. A primeira vertente utiliza o conceito de governamentalidade como uma ferramenta crítica, focando essencialmente na trajetória do liberalismo global. Essa vertente objetiva compreender como a expertise neoliberal se conforma em uma ferramenta de ampla eficácia no que tange a busca pela modificação dos processos relacionados à vida dos indivíduos (biopolítica) (ZANOTTI, 2013, p. 3). Em última instância, problematizam como as ferramentas biopolíticas e a própria violência se juntam para servir as classes dominantes ou as agendas políticas dos Estados (AGAMBEN, 1998; DUFFIELD, 2005; HARDT; NEGRI, 2000; MBEMBE, 2001; PROZOROV, 2007). Essa concepção é adotada como um instrumento que permite teorizar sobre as características globalmente opressivas do liberalismo internacional. Para a segunda vertente delineada por Zanotti, a governamentalidade se configura em uma ferramenta descritiva que possibilita explorar as modalidades do governo local e internacional (ZANOTTI, 2013, p. 2). Por conseguinte, tais análises focam nos efeitos da governamentalidade e nos contextos onde ela é operacionalizada. Essas pesquisas objetivam, principalmente, a compreensão e a análise sobre as práticas de governo e sobre as formas de resistência advindas dessas práticas (BIGO, 2002, 2011; JOSEPH, 2009, 2010; LIPSCHUTZ; ROWE, 2005; LOWENHEIM, 2007; MERLINGEN, 2006; WALTERS, 2012;).

Para Zanotti (2013, p. 3-4) a distinção entre essas duas abordagens da governamentalidade é central para refletir e debater sobre a ação política na esfera internacional. A primeira perspectiva, por mais que apresente uma crítica importante ao neoliberalismo acaba, segundo Zanotti, privilegiando teorizações abstratas e se afastando do principal foco da governamentalidade - a problematização do exercício do governo em um determinado espaço/tempo. Dessa maneira, esse tipo de análise reforça uma conceitualização liberal de sujeitos e poder, determinada por uma relação de dominação externa que impede que se reimagine a agência política daqueles que são dominados. Isso não quer dizer que essas análises não se configuram em contribuições importantes, uma vez expõem e problematizam o liberalismo como um quadro de dominação política e social. Porém, não se rompe totalmente com uma concepção do poder como um elemento essencialmente repressivo e da agência política como a busca pela liberação de sujeitos oprimidos. Nesse sentido, a se- 
gunda abordagem acaba por complementar a análise da governamentalidade em âmbito global, por um lado, trazendo para o centro do debate a preocupação sobre como se dá a operacionalização de estratégias de governo neoliberais e, por outro lado, destacando quais são os seus efeitos práticos nos contextos onde são aplicadas essas estratégias. Procura-se vislumbrar como a aplicação das normas de conduta advindas da ordem internacional neoliberal engendram movimentos de resistência, assimilação e transformação em ambientes que não são totalmente liberalizados (JOSEPH, 2010, p. 262).

Diante disso, pode-se apreender que a governamentalidade global é uma importante ferramenta analítica que permite compreender as técnicas utilizadas para moldar e até mesmo constranger a conduta dos atores no âmbito internacional. A partir da análise das racionalidades políticas pode-se compreender os quadros discursivos responsáveis por delimitar o campo de atuação possível na arena internacional. $\mathrm{Na}$ atualidade, o neoliberalismo é a mentalidade que norteia e delineia os cálculos e as práticas de governo. Todavia, uma investigação mais aprofundada sobre essas práticas indica que, por mais que o neoliberalismo conceda substância à governamentalidade global, as práticas de persecução dessas estratégias ainda combinam mecanismos disciplinares e técnicas mais sutis de governo - como a ajuda e a cooperação internacional.

Nesse sentido, o conceito de governamentalidade permite problematizar, no cenário internacional, a existência de técnicas e práticas de governo, que são operacionalizadas a partir de uma racionalidade política inerente às relações de poder internacionais. Logo, a ideia de governamentalidade global permite uma problematização mais qualificada das complexidades e as nuances práticas e racionalidades políticas que coordenam o sistema internacional, sobretudo com relação à disposição de uma ordem neoliberal (LIPSHUTZ, 2006, p. 13). É importante ressaltar que trazer a ideia governamentalidade global para entender as dinâmicas internacionais não implica em uma rejeição à soberania, mas sim, em uma tentativa de pensar a instrumentalização do poder dentro e fora dos Estados (JOSEPH, 2010, p. 225-226). Nesse sentido, a problematização dessa realidade a partir da noção de governamentalidade permite, por exemplo, observar e problematizar como no âmbito internacional uma complexa combinação de diferentes Estados, sociedades civis e formas de governo (JOSEPH, 2010, p. 234) atuam e interagem. Dessa forma, entende-se que a governamentalidade não fica mais retida apenas no âmbito do Estado e da sua sociedade, passando a se tornar um elemento importante para o funcionamento da política internacional. A governamentalidade, portanto, passa a estar relacionada com a consolidação de padrões de comportamento e interação e com a produção dos regimes de verdades em âmbito internacional.

A utilização da noção de governamentalidade global permite, seguindo Larner e Walters (2002, p. 415), a problematizar, inclusive, sobre diferentes tipos de governamentalidade, desde o imperialismo até a integração europeia. Dessa maneira, a ideia de governamentalidade global não conduz essencialmente a conclusão de que existe apenas uma única forma de governamentalidade na espera internacional. Pelo contrá- 
rio, pode-se observar o surgimento de racionalidades políticas distintas, voltadas a necessidades especificas e localizadas em contextos e tempos particulares. Esse tipo de análise possibilita que se observe como, por exemplo, a governamentalidade do imperialismo acaba por incorporar elementos autoritários, fomentando um governo internacional por meio da disciplina e da sujeição dos agentes envolvidos às metrópoles capitalistas. Enquanto, a governamentalidade do regionalismo engendra o governo dos Estados e das populações a partir do consentimento ativo dos mesmos (LARNER; WALTERS; 2002, p. 398). Dessa forma, quando se pensa sobre a governamentalidade contida na integração europeia claramente observa-se uma racionalidade neoliberal, permeada por uma concepção descentralizada de poder e pelo governo à distância (LARNER; WALTERS; 2002, p. 398).

Tendo em conta a discussão apresentada nesse artigo, percebe-se que a problematização da política internacional a partir da noção de governamentalidade permite uma reflexão mais refinada acerca da mesma, uma vez que possibilita a visualização da operacionalização do poder por meios menos visíveis e mais indiretos; apesar desses meios não serem menos invasivos e profundos. Assim, pode-se afirmar que a governamentalidade global possibilita o estudo de como o governo, como conduta da conduta, trabalha à distância, empregando novas técnicas de observação, de cálculos e de administração para regular a esfera internacional (JOSEPH, 2009, p. 415). Consequentemente tal noção é fundamental para melhor compreender as práticas e racionalidades exercidas pelos agentes internacionais com o fim de buscar moldar o campo de atuação de Estados e populações. Nesse mesmo sentido, a governamentalidade opera, orienta e constrói significações a respeito do internacional a partir de centros de produção de conhecimento teórico, técnico e econômicos sobre as dinâmicas relacionais dos atores internacionais. Assim, baseando-se no conhecimento e práticas de governo, culmina-se no exercício de poder de modo a produzir normas de conduta para os agentes internacionais.

Conclusão

No decorrer desse artigo pode-se observar que há uma série de estudos que incorporam a noção de governamentalidade como uma forma de compreender o domínio internacional a partir das múltiplas racionalidades e tecnologias de poder que incidem sobre, através e além dos Estados. Dessa maneira, a governamentalidade global permite uma melhor e mais refinada problematização das relações de poder presentes no cenário internacional. Tal noção permite, sobretudo, evidenciar as racionalidades nas quais tais operacionalizações de poder se assentam. Isso é possível porque o estudo da conformação de uma governamentalidade global permite que se observe como o poder é exercido por meio de uma rede de conhecimentos, instituições, práticas e procedimentos reguladores da conduta dos Estados e das suas populações. Consequentemente, é possibilitada uma melhor compreensão de como as racionalidades políticas acabam se conformando em regimes de práticas, que por sua vez 
desenham a forma de atuação do governo, entendido enquanto a conduta de condutas. (DEAN, 2010, p. 23). Mais especificamente, a problematização da política internacional a partir da noção de governamentalidade global permite uma análise mais aprofundada e clara dos diferentes mecanismos de poder e de governo que acabam por conformar no cenário internacional regimes de práticas específicos que visam à conduta da conduta em âmbito global. Nesse sentido, a governamentalidade ilumina não apenas o modo como as práticas e as instituições internacionais incide sobre os Estados e as suas populações, como também destaca quais as mentalidades de governo fundamentam tais práticas.

Pode-se observar que atualmente as relações internacionais, quando analisadas a partir da ótica da governamentalidade, são constituídas majoritariamente por regimes de práticas e quadros discursivos neoliberais. Essa característica, no entanto, constitui-se no resultado de processos históricos, sociais e políticos que dão forma e substância às múltiplas técnicas e mecanismos governo. Isso porque, por meio de uma analítica de governo pode-se, por um lado, identificar como racionalidades políticas específicas tornam-se centrais ao exercício do governo e, por outro lado, visualizar quais quadros discursivos são obscurecidos por essas racionalidades. Assim, a noção de governamentalidade, ao vincular as mentalidades com as práticas políticas, desnaturaliza a frequente a associação entre as formas de governamento existentes no espaço internacional e a conformação de uma racionalidade política neoliberal dominante. Por conseguinte, os estudos sobre a governamentalidade global, em última instância, possibilitam que se problematize os modos por meios dos quais os regimes e as técnicas de governança atuais surgiram, se consolidaram e passaram a normatizar condutas dentro da política internacional.

$$
\text { Referências }
$$

ADORNO, Theodor; HORKHEIMER, Max. Dialética do Esclarecimento: fragmentos filosóficos. Rio de Janeiro: Zahar, 1985.

AGAMBEN, Giorgio. Homo Sacer: Sovereign Power and Bare Life. Stanford: Stanford University Press, 1988

ASHLEY, Richard. The Geopolitics of Geopolitical Space: toward a critical social theory of international politics. Alternatives: Global, Local, Political. [s.l], v. 12, n. 4, p. 403-434. 1 out. 1987.

ASHLEY, Richard. Untying the Sovereign State: A Double Reading of the Anarchy Problematique. Millennium. [s.l], v. 17, n. 2, p. 227-262. 1 jun. 1988.

BARTELSON, Jens. A Genealogy of Sovereignty. Cambridge: Cambridge University Press, 1995.

BIGO, Didier. Security and immigration: Toward a critique of the governmentality of unease. Alternatives: Global, Local, Political. [s.l], v. 27, n. 1, p. 63-92. 1 fev. 2002.

BIGO, Didier. Pierre Bourdieu and International Relations: Power of Practices, Practices of Power. International Political Sociology. [s.l], v. 5, n. 3, p. 225-258. 14 set. 2011.

BLACKBURN, Simon. Dicionário Oxford de filosofia. Rio de Janeiro: Zahar, 1997.

BLANCO, Ramon. Peace as government: the (Bio)Politics of State-Building. 2013. $360 \mathrm{f}$. Tese (Doutorado) - Curso de Relações Internacionais, Universidade de Coimbra, Coimbra, 2013.

BLANCO, Ramon. Normalizando anormais na sociedade internacional: Operações de paz, Foucault e a Escola Inglesa. Relações Internacionais. [s.l], n. 53, p. 83-107. Março 2017. 
BLANCO, Ramon. Peace as Government: The Will to Normalize Timor-Leste. London: Lexington Books, 2020.

CASTRO, Susana de. Ontologia. Rio de Janeiro: Zahar, 2008.

CASTRO, Thales. Teoria das relações internacionais. Brasília: Fundação Alexandre de Gusmão (FUNAG), 2012.

COMMISSION ON GLOBAL GOVERNANCE. Our global neighbourhood. Oxford: Oxford University Press, 1995.

COX, Robert. Social Forces, States and World Orders: Beyond International Relations Theory. Millennium. [s.l], v. 10, n. 2, p. 126-155. 1 jun. 1981.

DEAN, Mitchell. Governmentality: Power and Rule in Modern Society. Londres: SAGE Publications, 2010

DELEUZE, Gilles. Foucault. Minneapolis: University of Minnesota Press, 2006.

DUFFIELD, Mark. Development, Security and Unending War: Governing the World of Peoples. Cambridge: Polity Press, 2005.

FOUCAULT, Michel. Prisons et asiles dans le mécanisme du pouvoir. In: Dits et Ecrits, t. II. Paris: Gallimard, 1976-1988.

FOUCAULT, Michel. Os Anormais: cursos do College de France. São Paulo: Editora WMF, 2010. FOUCAULT, Michel. Society Must Be Defended. New York: Picador, 2003.

FOUCAULT, Michel. Security, Territory, Population. Basingstoke: Palgrave Macmillan, 2007. FOUCAULT, Michel. The Birth of Biopolitics. Basingstoke: Palgrave Macmillan, 2008.

FOUCAULT, Michel. The Birth of the Clinic. New York: Vintage, 1975.

FOUCAULT, Michel. Microfísica do poder. Rio de Janeiro: Graal, 1979.

FOUCAULT, Michel. Truth and power. In: GORDON, Colin. (ed.). Power/ Knowledge. Brighton: Harvester, 1980.

FOUCAULT, Michel. Governmentality. In: BURCHELL, Graham; GORDON, Colin; MILLER, Peter (eds.). The Foucault Effect: Studies in Governmentality. Chicago: University of Chicago Press, 1991

FOUCAULT, Michel. A arqueologia do saber. Rio de Janeiro: Forense Universitária, 2002. FOUCAUlT, Michel. Vigiar e Punir: Nascimento da Prisão. Petrópolis: Editora Vozes, 2014. FUKUYAMA, Francis. The End of History and the Last Man. New York: Free Press, 1992.

GEORGE, Jim. Discourses of Global Politics: A critical (Re)Introduction to International Relations. Boulder: Lynne Rinner, 1994.

GORDON, Colin. Governmental rationality: An introduction. In: BURCHELL, et. al. (eds.). The Foucault effect: Studies in governmentality. Chicago: University of Chicago Press, 1991.

HARDT, Michael; NEGRI, Antonio. Empire. Cambridge: Harvard University Press, 2000.

HAYWARD, Clarissa Rite. 2000. De-Facing Power. Cambridge : Cambridge University Press.

HUTCHINGS, Kimberly. Foucault and International Relations Theory. In: LLOYD, Moya; THACKER, Andrew. (eds). The Impact of Michel Foucault in the Social Sciences and Humanities. Basingstoke: Palgrave Macmillan, 1997.

JERVIS, Robert. Realism in the Study of World Politics. International Organization. Cambridge, v. 52, n. 4, p. 971-991, 1998.

JOSEPH, Jonathan. Governmentality of What? Populations, States and International Organisations. Global Society. [s.l], v. 23, n. 4, p. 413-427. 9 out. 2009.

JOSEPH, Jonathan. What Can Governmentality Do for IR?. International Political Sociology. [s.l], v. 4, n. 2, p. 202-205. 7 jun. 2010.

JOSEPH, Jonathan. The limits of governmentality: Social theory and the international. European Journal of International Relations. [s.l], v. 16, n. 2, p. 223-246. 16 abr. 2010.

KELLY, Mark G. E. The Political Philosophy of Michel Foucault. New York: Routledge, 2009. LARNER, Wendy; WALTERS, William. Global Governmentality: Governing international spaces. Canada: Routledge, 2004. 
LARNER, Wendy; WALTERS, William. The political rationality of the 'new regionalism': Toward a genealogy of the region. Theory \& Society. [s,l], v. 31, n. 3, p. 391-432, jun. 2002.

LEMKE, Thomas. Foucault, Governmentality, and Critique. Rethinking Marxism. [s.l], v.14, n. 3, p. 49-64. 7 dez. 2010.

LEMKE, Thomas. An indigestible meal? Foucault, governmentality and state theory. Distinktion: Scandinavian Journal of Social Theory. [s.l], v. 8, n. 2, p. 43-64. 1 mar. 2011

LEMKE, Thomas. Os Riscos da Segurança: liberalismo, biopolítica e medo. In: Governamentalidade: Segurança. AVELINO, Nildo; VACCARO, Salvo. (orgs.). São Paulo: Intermeios, 2014.

LIPSCHUTZ, Ronnie; ROWE, James. Globalization, Governamentality and Global Politics: regulation for the rest of us?. New York: Routledge, 2006.

LOWENHEIM, Oded. The Responsibility to Responsibilize: Foreign Offices and the Issuing of Travel Warnings. International Political Sociology. [s.l], v. 1, n. 3, p. 203-221, ago. 2007.

MACHADO, Roberto. Introdução: Por uma genealogia do Poder. In: FOUCAULT, Michel. A Microfísica do Poder. Rio de Janeiro: Edições Graal, 1979.

MAIA, Antônio. Sobre a analítica do poder de Foucault. Tempo Social. [s.l], v. 7, n.1/2, p. 83103. 1995. Disponível em: http://www.revistas.usp.br/ts/article/view/85208/88047. Acesso em: 1 set. 2018.

MERLINGEN, Michael. Foucault and World Politics: Promises and Challenges of Extending Governmentality Theory to the European and Beyond. Millennium: Journal of International Studies. [s.l], v. 35, n. 1, p. 181-196. 1 dez. 2006.

MORAVCSIK, Andrew. The New Liberalism. In: REUS-SMIT, Christian; SNIDAL, Duncan. The Oxford Handbook of International Relations. Oxford: Oxford University Press, 2008.

MORGENTHAU, Hans. Politics Among Nations. New York: Alfred A. Knopf, Inc, 1948.

NEAL, Andrew. Michel Foucault. In: EDKINS, Jenny; VAUGHAN-WILLIAMS, Nick. (Eds.). Critical Theorists and International Relations. London: Routledge, 2009.

NOGUEIRA, João Pontes; MESSARI, Nizar. Teoria das Relações Internacionais: correntes e debates. Rio de Janeiro: Elsevier, 2008.

PAOLINI, A. J. Foucault, realism and the power discourse in International Relations. Australian Journal of Political Science. [s.l], v. 28, n.1, p. 98-117. 21 set. 2007.

POGREBINSCHI, Thamy. Foucault, para além do Poder Disciplinar e do Biopoder. Lua Nova. São Paulo, v. 64, p. 179-201, 2004. Disponível em: http://www.scielo.br/pdf/ln/n63/a08n63.pdf. Acesso em: 12 ago. 2018.

PROZOROV, Sergei. Foucault, Freedom, and Sovereignty. Burlington: Ashgate, 2007.

ROSE, Nikolas. Powers of Freedom: Reframing Political Thought. London. Cambridge: Cambridge University Press, 2004.

ROSE, Nikolas; MILLER, Peter. Political Power Beyond the State: Problematics of Goverment. British Journal of Sociology. [s.l], v. 43, n. 2, p. 172-205. 15 jan. 2010.

ROSENAU, James. Governança, ordem e mudança na política mundial. In: ROSENAU, James; CZEMPIEL, Ernst-Otto. Governança sem governo: ordem e transformação na política mundial. Brasília: Unb, 2000.

SELBY, Jan. Engaging Foucault: Discourse, Liberal Governance and the Limits of Foucauldian IR. International Relations. [s.l], v. 21, n. 3, p. 324-345. 1 set. 2007.

SENDING, Ole Jacob; NEUMANN, Iver. Governance to Governmentality: Analyzing NGOs, States, and Power. International Studies Quarterly. [s.l], v. 50, n. 3, p.651-672, set. 2006.

SHAPIRO, Michael. Violent Cartographies: Mapping Cultures of War. Minneapolis: University of Minnessota Press, 1997.

SHAPIRO, Michael. Cinematic Political Thought: Narrating Race, Nation and Gender. New York: New York University Press, 1999.

SILVA, Marco Antonio de Meneses. Teoria Crítica em Relações Internacionais. Contexto Internacional. Rio de Janeiro, v. 27, n. 2, p. 249-282, dez. 2005. Disponível em: https://www.scielo.br/ pdf/cint/v27n2/v27n2a01.pdf. Acesso em: 12/08/2019. 
WALKER, Rob. Inside/Outside: International Relations as Political Theory. Cambridge: Cambridge University Press, 1993.

WALTERS, William. Governmentality: Critical Encounters. London: Routledge, 2012.

WALTZ, Kenneth. Theory of International Politics. New York: McGraw-Hill, 1979.

WEBER, Cynthia. Simulating Sovereignty: Intervention, the State and Symbolic Exchange. Cambridge: Cambridge University Press, 1995.

WEBER, Max. Economia e sociedade: fundamentos de sociologia compreensiva. Brasília: Editora UnB, 1999.

ZANOTTI, Laura. Governmentalizing the post-Cold War international regime: The UN debate on democratization and good governance. Alternatives: Global, Local, Political. [s.l], v. 30, n. 1, p. 461-487. 1 out. 2005.

ZANOTTI, Laura. Governmentality, Ontology, Methodology: Re-thinking Political Agency in the Global. Alternatives: Global, Local, Political. [s.l], v. 38, n. 4, p. 288-304. 30 dez. 2013 